\title{
Brasil: localización industrial y encadenamientos sectoriales, el caso de la industria automovilística
}

\author{
Luciano Ferreira Gabriel, Antonio Claudio de Gama \\ Cerqueira y Luiz Carlos Ribeiro
}

RESUMEN

Este trabajo tiene como objetivo presentar un análisis de la distribución espacial de la industria automotriz en el Brasil, entre 1995 y 2011, en relación con sus diversas categorías económicas, y mostrar sus encadenamientos sectoriales mediante las matrices interregionales de insumo-producto. A partir del cálculo del coeficiente de localización $\left(Q L_{i j}\right)$ de dicho período, se constató que la tercera ola de inversiones, iniciada en la segunda mitad de los años noventa, logró producir, de hecho, una ligera desconcentración espacial de este sector en la economía nacional. El cálculo del coeficiente de asociación geográfica $\left(C A_{i k}\right)$ de diferentes años indicó una pequeña disminución, pese a que se mantuvo un nivel significativo de concentración, lo que sugiere que la producción de vehículos es un proceso bastante integrado con otras actividades económicas. Esta integración se corroboró, especialmente, con respecto a la compra de insumos (efectos hacia atrás) en todas las regiones aquí analizadas.

PALABRAS CLAVE

CLASIFICACIÓN JEL

AUTORES
Localización industrial, industria automotriz, inversiones, producción industrial, estadísticas industriales, Brasil

R11, R12, R30

Luciano Ferreira Gabriel es Doctorando en Economía en la Universidad Federal de Minas Gerais (UFMG), Centro de Desarrollo y Planeamiento Regional (cedeplar), Brasil. lucianofg@gmail.com

Antonio Claudio de Gama Cerqueira es Doctorando en Economía en la Universidad Federal de Minas Gerais (ufmG), Centro de Desarrollo y Planeamiento Regional (cedePlAR), Brasil. antonio.gamacerqueira@ gmail.com

Luiz Carlos Ribeiro es Doctorando en Economía en la Universidad Federal de Minas Gerais (Ufmg), Centro de Desarrollo y Planeamiento Regional (cEDEPLAR), Brasil. ribeiro.luiz84@gmail.com 


\section{I}

\section{Introducción}

La principal actividad del sector automotor es el ensamblaje de vehículos y constituye un oligopolio global formado por un pequeño número de grandes empresas internacionalizadas, que se organizan en diversas aglomeraciones productivas (clusters) en diferentes países. Para comprender el comportamiento de este mercado es fundamental tomar en cuenta las grandes economías de escala y de aglomeración, entre otras barreras para la entrada en el proceso de producción de un automóvil.

Según Costa y Henkin (2011, pág. 4), las ensambladoras suelen disponer de diferentes plantas para el proceso de fabricación -incluso con especialización por tipo de vehículo y plataforma fabricada— que permiten variaciones de los modelos para las ensambladoras que se utilizan. En Ferraz, Kupfer y Haguenauer (1996) y Casotti y Goldenstein (2008) se constata que este sector está en permanente proceso de consolidación y en él son frecuentes la creación de empresas, las fusiones, las empresas conjuntas y las asociaciones comerciales de los tipos más diversos que, en general, reafirman la estructura de mercado "oligopolizado" del sector.

Además de la gran importancia que este oligopolio global representa para la economía, las empresas que integran el sector han sido precursoras en el desarrollo de nuevas tecnologías y de nuevos modelos de gestión de las fábricas, como se señala en Casotti y Goldenstein (2008, pág. 149). En términos tecnológicos, el sector automotor incluye a las empresas que más actividades tecnológicas realizan de un grupo de empresas multinacionales de 45 sectores de la economía brasileña ${ }^{1}$.

En diferentes países, la producción de automóviles y el empleo en el sector suelen organizarse en aglomeraciones productivas en algunas regiones. De acuerdo con Sturgeon, Biesebroeck y Gereffi (2008, pág. 9), en ciertos casos estos clusters se especializan en aspectos específicos, como el diseño de los vehículos, el ensamblaje final o la manufactura de partes con características en común, como el contenido electrónico o la intensidad del factor trabajo.

\footnotetext{
${ }^{1}$ Albuquerque (2000) realiza este análisis a partir de un indicador de internalización relativa de actividades tecnológicas.
}

Sturgeon, Biesebroeck y Gereffi (2008) explican que, en el contexto de la compleja geografía económica de la industria automotriz, la integración mundial ha llegado a uno de los niveles más profundos de la relación entre compradores y vendedores, sobre todo en el caso de las ensambladoras y sus proveedores principales. Este proceso implica que la producción tiende a organizarse, de manera regional o nacional, para la producción masificada de modelos específicos de vehículos en locales próximos a las plantas de las ensambladoras, de modo que se incrementen las ventajas logísticas de tiempo de entrega, las economías de escala y el ahorro de costos laborales.

En este marco general, el Brasil dispone de un gran mercado nacional (tanto real como potencial), un completo parque industrial, una sólida base de ingeniería relacionada con la industria automotriz y una red de concesionarios con una amplia presencia nacional. Al analizar la distribución geográfica de la producción de vehículos en el Brasil y la participación en el mercado de las principales ensambladoras, se perciben claramente las características mencionadas anteriormente.

Dada esta compleja geografía económica, el presente trabajo tiene como objetivo presentar un análisis de la distribución espacial de la industria automotriz en el Brasil, entre 1995 y 2011, a partir de sus diversas categorías económicas, y mostrar además sus encadenamientos sectoriales por medio del análisis de los índices de eslabonamiento de Hirschman-Rasmussen y los multiplicadores de producción, sobre la base de los datos de su matriz de insumo-producto interregional para 2004 (la matriz pública disponible más reciente).

Entre las medidas de localización y especialización existentes en la bibliografía, dos se pueden destacar como las más utilizadas: el coeficiente de localización $\left(Q L_{i j}\right)$ y el coeficiente de asociación geográfica $\left(C A_{i k}\right)$. El coeficiente $Q L_{i j}$ se utilizó para determinar la localización de la industria de transformación en el Brasil entre 1994 y 2009 (Rezende, Campolina y Paixão, 2013) y la distribución geográfica de industrias creativas y culturales en España, Italia y el Reino Unido de Gran Bretaña e Irlanda del Norte (Basset, Griffiths y Smith, 2002; García, Fernández y Zobio, 2003; Lazzeretti, Boix y Capone, 2008). Albuquerque y otros (2002) utilizaron el coeficiente $C A_{i k}$ para analizar la vinculación entre 
indicadores de ciencia y tecnología y las instalaciones urbanas, en una amplia gama de municipios del Brasil.

Para llevar a cabo el objetivo propuesto, el trabajo se divide como se indica a continuación. Después de esta breve Introducción, en la sección II se presentan algunos aspectos preliminares de la industria automovilística que ayudan a explicar, en cierta medida, la distribución espacial de las empresas (principalmente las ensambladoras). En la sección III se realiza un análisis regional de la industria automotriz en el Brasil, para evaluar sus encadenamientos sectoriales. En la sección IV se muestra la distribución geográfica de la industria automotriz en el Brasil por medio del análisis de los coeficientes de localización y de asociación geográfica. Finalmente, en la sección V se presentan las consideraciones finales.

\section{II}

\section{La industria automovilística: algunos aspectos preliminares}

La estructura de mercado de la industria automotriz es un oligopolio a nivel internacional y existen grandes barreras que dificultan la entrada en ella. En cada país, esta industria se presenta como un oligopolio diferenciado y, a la vez, concentrado. Hay una división del trabajo dentro de la cadena de valor del producto (vehículo automotor), con los centros de decisión y de investigación y desarrollo (I+D) localizados en los países sede y la fabricación dispersa internacionalmente, según Costa y Henkin (2011, pág. 4).

En ese contexto, las plantas industriales están situadas cerca de los principales mercados consumidores (elemento esencialmente "weberiano" ${ }^{2}$ ), debido a los costos de flete y de las barreras arancelarias (elementos destacados por Lösch ${ }^{3}$ ), a las diversas políticas de apoyo al sector, a los menores costos de producción y al resto de ventajas vinculadas a la localización. Por otra parte, Costa y Henkin (2011) explican qué parte de la producción se dirige a los mercados y regiones donde están situadas las plantas, con la consiguiente configuración de plataformas regionales.

\footnotetext{
${ }^{2}$ En el contexto de la teoría de la localización, la cuestión fundamental que Weber (1929) procura responder consiste en determinar dónde se producirá la localización de una unidad productiva en el espacio, tomando en cuenta las condiciones económicas de producción y distribución. Para esto, el autor construyó un modelo que parte de la constatación empírica verificable de que las materias primas no están distribuidas de forma homogénea en el espacio. De esta forma, las empresas procurarán situarse en el lugar geográfico que optimice los costos de transporte.

${ }^{3}$ Lösch (1954) tomó los retornos crecientes como esenciales para la formación del espacio económico y elaboró un modelo basado en la competencia monopolística, como Kaldor. Lösch argumenta que los incrementos de las economías de escala conducen al aumento de la oferta global de la empresa en el espacio, al ampliar el área de mercado.
}

En la fase actual, el mercado relacionado con la industria automotriz presenta un alto nivel de competencia debido a la saturación de algunos mercados y de su mayor madurez. Esa característica induce a las grandes empresas a explorar nuevas oportunidades de crecimiento y lucro en países emergentes, como el Brasil (Senhoras, 2005).

Algunas de las principales estrategias adoptadas por dichas empresas, dadas estas características, son la búsqueda de diferenciación de sus productos, las asociaciones, las alianzas y, ante todo, la internacionalización de sus actividades.

La industria automotriz presenta algunas características relevantes, como por ejemplo, las economías de escala y de aglomeración y el nivel de intensidad tecnológica necesario para la producción de un vehículo, que hacen que se requiera un elevado volumen de capital inicial para que una empresa pueda acceder al mercado, lo que da lugar a significativas barreras de entrada.

Marshall (1985) enfatiza los efectos positivos derivados de la aglomeración al estudiar los distritos industriales localizados cerca de las grandes ciudades, donde surgen naturalmente varios tipos de externalidades, clasificadas en tres tipos principales: i) economías de escala, internas a las empresas, relativas a la reducción de los costos medios con el aumento de la producción; ii) economías de localización, externas a las empresas e internas al sector, relacionadas con los beneficios generados por la aglomeración de proveedores, subcontratados y socios, debido a la especialización productiva, y iii) economías espaciales, externas a las empresas y al sector, causadas por el incremento del capital social en la región. 
La configuración espacial de las actividades económicas o concentración industrial es el resultado de dos tipos de fuerzas opuestas: las de aglomeración y las de dispersión. Generalmente, las primeras suelen ser causadas por las tres externalidades "marshallianas", según se ha indicado anteriormente. Por su parte, las fuerzas de dispersión (también denominadas efectos de congestión (congestion effects)) consisten en la falta de movilidad de la mano de obra, los costos de transporte y los efectos externos del medioambiente, entre otros factores.

El mecanismo generador de las externalidades, relacionado con los retornos crecientes, se basa en las fuerzas de interacción del mercado según Freitas (2012) y se relaciona con las transacciones de la empresa con proveedores (eslabonamientos hacia atrás o backward linkages) y con sus transacciones con los consumidores (eslabonamientos hacia delante o forward linkages). De esta forma, el enfoque de Marshall se centra en el efecto de los mecanismos de mercado y otorga un carácter pecuniario a las externalidades, como determinantes de la aglomeración y dispersión espacial de la industria.

De acuerdo con Camargo (2006, pág. 115), se puede afirmar que la localización de las empresas de la industria automotriz, en el ámbito de un país en desarrollo, depende de factores de situación relativos a las economías y deseconomías de aglomeración, como las características del mercado de trabajo, el costo del suelo urbano y las condiciones de infraestructura urbana y de prestación de servicios, manifestadas en la estructura viaria, en la existencia de escuelas y universidades o en la logística, entre otras características. En el caso del Brasil, en particular, todavía hay factores de tipo fiscal y tributario que ejercen una significativa influencia en la estructura situacional y en la implantación de nuevas unidades de producción.

Según Camargo (2006, págs. 116-117), las ensambladoras crearon generalmente una estructura de gobernanza institucional que permitía reproducir las economías de especialización para una explotación más intensa de sus activos. Sin embargo, posteriormente se produjo una intensa flexibilización de los requisitos de localización, que permitió que esas empresas y su red de proveedores pudieran instalarse en lugares más distantes de los principales mercados consumidores.

La interacción entre los eslabonamientos hacia delante y hacia atrás descritos por Hirschman (1961) posibilita una serie de retornos de escala crecientes, externos a la empresa, pero internos a la aglomeración local, que incluyen la reducción de los costos de transacción. La posibilidad de crear economías de especialización, según
Camargo (2006), redujo la importancia de las economías de urbanización ${ }^{4}$ y permitió que las ensambladoras evitaran las deseconomías de aglomeración y se instalaran en centros urbanos menores y más distantes, aunque la mayoría de las veces tuvieran que permanecer en el radio suburbano del centro metropolitano con la función de "lugar central" de nivel superior.

Además, la industria automotriz es una excelente candidata a generar grandes efectos multiplicadores en la estructura productiva, debido a sus relaciones intersectoriales con diversos segmentos, principalmente hacia atrás en la cadena productiva. Ribeiro y otros (2010), y Ribeiro, Montenegro y Pereira (2013), por ejemplo, señalaron que este sector, en Bahia y Minas Gerais, mostraba encadenamientos hacia atrás por sobre el promedio de sus estados respectivos.

A partir del estudio de Freitas (2012, pág. 15), la bibliografía sobre economías de aglomeración relaciona el crecimiento de la actividad industrial con los incrementos de productividad de las empresas, procedentes de las economías externas de escala, o externalidades locales, de acuerdo con la estructura productiva de la región. Según este autor, estas economías de aglomeración pueden dividirse - dependiendo del contexto- en estáticas y dinámicas. En un contexto estático, dichas economías se refieren a los aumentos de productividad causados por el ambiente industrial actual, mientras que en un contexto dinámico, ellas consisten en las interacciones entre los agentes del pasado que afectan a la productividad actual.

Conjugando los factores de macrolocalización y de microlocalización de la ensambladora y los proveedores, Camargo (2006, pág. 118) explica que:

“(...) la determinación de la localización de una red local de proveedores depende inicialmente de una determinación de la macrolocalización, relacionada con la estrategia competitiva de la ensambladora. La determinación de la microlocalización está vinculada a factores de aglomeración y desaglomeración, que afectan el proceso de formación y organización de la red e influyen en la concentración de las empresas proveedoras de primer nivel, mientras que la localización de las demás empresas de los

\footnotetext{
${ }^{4}$ Según Freitas (2012), se puede observar que la urbanización adquiere un papel prominente por el hecho de recibir una parte significativa de las inversiones públicas y presentar ventajas de economías de aglomeración. Ante el aumento de los costos urbanos de los principales polos de producción, como consecuencia de su modernización, desde mediados de 1980, en la economía brasileña se inició un proceso de reversión del nivel de concentración geográfica que se ha ido intensificando durante los últimos años, al igual de lo que ha sucedido en la industria automotriz.
} 
siguientes niveles en la jerarquía de la red dependerá del tipo y de la naturaleza de su producto, de su grado de transportabilidad y de los factores de localización determinados por la especificidad del lugar en el que se inserte la red".

Dada la importancia de los encadenamientos productivos en la creación de externalidades y en la formación de aglomeraciones, en la sección III se realiza un análisis regional de la industria automotriz en el Brasil por medio de indicadores construidos a partir de las matrices interregionales de insumo-producto, estimadas por Joaquim Guilhoto para el año $2004^{5}$, de acuerdo con los procedimientos descritos en Guilhoto y Sesso Filho (2005) y Guilhoto y otros (2010).

${ }^{5}$ No hay matrices interregionales más recientes disponibles para el Brasil.

\section{III}

\section{Encadenamientos sectoriales de la industria automotriz en el Brasil}

La utilización de modelos interregionales de insumoproducto, según Miller y Blair (2009), resulta más recomendable que los modelos especificados para una sola región. Esto se debe a que, al realizar un modelo uni-regional, no se captan las interrelaciones entre unidades espaciales, es decir, esa región queda aislada o desconectada del resto del país en que está inserta. Asimismo, según esos autores, la estructura básica de un modelo de insumo-producto interregional para dos regiones se puede representar de la siguiente manera. Supóngase un modelo con dos regiones, L y M:

$$
Z=\left[\begin{array}{ccc}
Z^{L L} & \vdots & Z^{L M} \\
\cdots & \cdots & \cdots \\
Z^{M L} & \vdots & Z^{M M}
\end{array}\right]
$$

donde $Z^{L M}$ son los flujos interregionales (por ejemplo, las exportaciones de la región $L$ ) y $Z^{L L}$ representan los flujos intrarregionales (por ejemplo, el comercio dentro de la región $L$ ). Después de algunas manipulaciones algebraicas, la solución de este modelo puede expresarse por medio de la ecuación (2):

$$
x=(I-A)^{-1} f
$$

donde $x$ y $f$ son, respectivamente, los vectores de producción y demanda final; $A$ se refiere a la matriz de coeficientes técnicos $a_{i j}$, definida como la cantidad de productos utilizados como insumos intermedios por el sector $i$ para producir una unidad monetaria de producto del sector $j$, para $i, j=1, \ldots, n$; y $(I-A)^{-1}$ es la matriz inversa de Leontief.
Con el propósito de verificar la estructura de encadenamiento regional de la industria automotriz en el Brasil, se presentan para el año 2004: i) el destino de las ventas para los componentes de la demanda intermedia y final, y ii) el origen de las compras.

En el gráfico 1 se muestra el destino de las ventas totales de vehículos automotores en 2004, según la producción de los nueve estados brasileños principales. Se puede percibir claramente un comportamiento heterogéneo en relación con el destino de la producción. En Santa Catarina y en Rio Grande do Sul, el mayor porcentaje corresponde al consumo intermedio, mientras que en Bahia y Goiás, este componente muestra el menor porcentaje. Río de Janeiro y Santa Catarina, en términos relativos, fueron las principales plataformas de exportación en 2004 , con porcentajes del $44 \%$ y del $32,5 \%$ de sus ventas totales, respectivamente. La producción de Goiás, por su parte, se destinó mayoritariamente a atender el consumo de las familias $(58,1 \%)$.

En los estados seleccionados, un $66,1 \%$ de la producción de vehículos automotores, en promedio, tuvo como destino la demanda final. En consecuencia, se puede esperar que se produzca un reducido efecto de encadenamiento hacia adelante de la cadena productiva referente a este sector, como se indica a continuación.

En el gráfico 2 se aprecia el origen de las compras de la industria automotriz. A diferencia de lo sucedido con el destino de las compras, aquí se puede percibir un patrón más homogéneo entre los estados. El componente importado, por ejemplo, presenta la menor participación en todos los estados analizados (10,9\% en promedio). En 2004, Río de Janeiro y São Paulo fueron los estados donde esa industria importó más insumos en términos relativos, con porcentajes del $17 \%$ y del $15,5 \%$, respectivamente. 
GRÁFICO

Brasil (estados seleccionados): destino de las ventas de la industria automotriz, 2004 (En porcentajes)

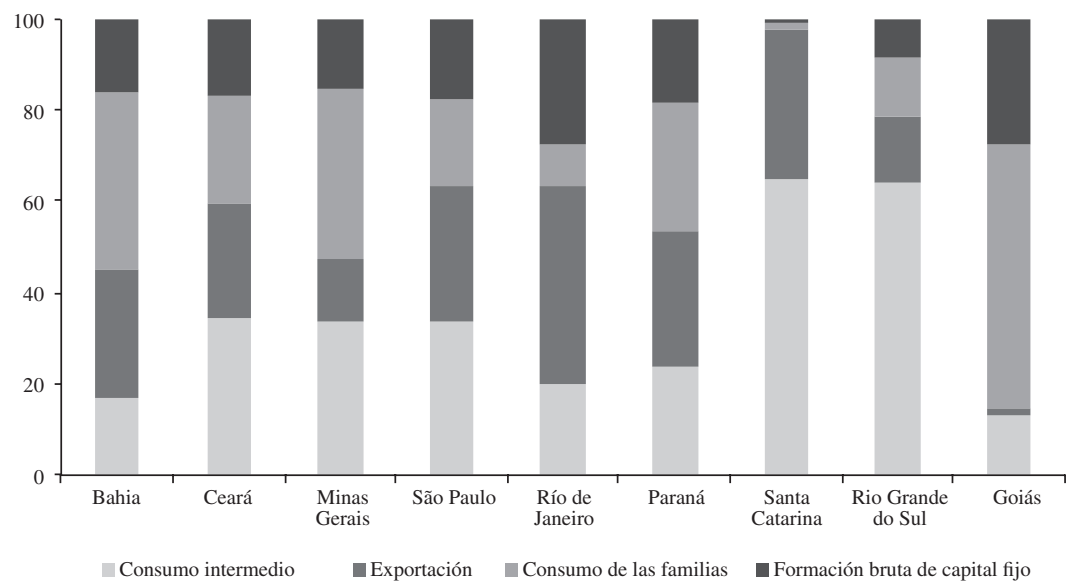

Fuente: Elaboración propia sobre la base de J.J.M. Guilhoto y U.A. Sesso Filho, "Estimação da matriz insumo-produto a partir de dados preliminares das contas nacionais", Economia Aplicada, vol. 9, № 2, 2005; J.J.M. Guilhoto y otros, Matriz de insumo-produto do Nordeste e Estados: metodologia e resultados, Fortaleza, Banco do Nordeste, 2010.

GRÁFICO 2

Brasil (estados seleccionados): origen de las compras de la industria automotriz, 2004 (En porcentajes)

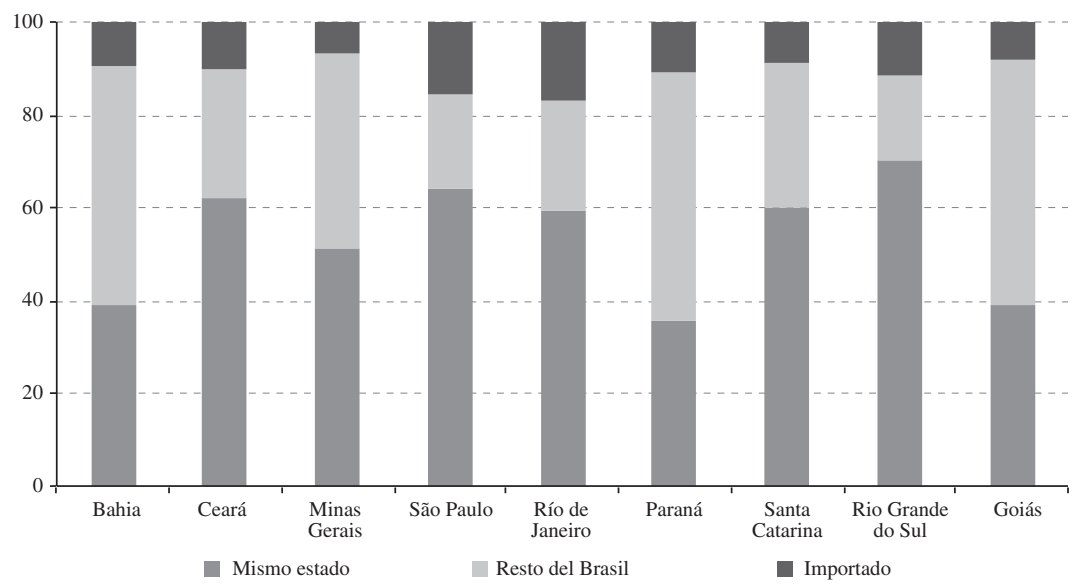

Fuente: Elaboración propia sobre la base de J.J.M. Guilhoto y U.A. Sesso Filho, "Estimação da matriz insumo-produto a partir de dados preliminares das contas nacionais", Economia Aplicada, vol. 9, № 2, 2005; J.J.M. Guilhoto y otros, Matriz de insumo-produto do Nordeste e Estados: metodologia e resultados, Fortaleza, Banco do Nordeste, 2010.

El estado con la producción más autosuficiente, es decir, aquel que dependió sobre todo de insumos cuyo origen estaba en el propio estado, fue Rio Grande do Sul $(70,3 \%)$, seguido por São Paulo $(63,8 \%)$ y Ceará $(63,1 \%)$. Teóricamente, esto indica que en esos estados hubo condiciones favorables que causaron la instalación de industrias proveedoras de materias primas para el sector automotor. Por otra parte, Paraná, Goiás y Bahia recibieron del resto del Brasil más de la mitad del total de sus compras, con participaciones del 53,6\%, el 53,1\% y el $51,1 \%$, respectivamente.

Es sabido que las relaciones hacia atrás (compra de insumos) de la industria automotriz implican un más elevado número de actividades, lo que sugiere una mayor importancia de los encadenamientos hacia atrás, en detrimento de los encadenamientos hacia adelante. 
Para comprobar esta suposición, se calcularon los índices de eslabonamiento de Hirschman-Rasmussen ${ }^{6}$ (véase el cuadro 1), que muestran si las relaciones de compras y ventas de los sectores están por sobre o por debajo del promedio de la economía.

Se puede observar que los índices hacia atrás (backward) de la industria automotriz eran superiores a 1 en todos los estados analizados, mientras que todos los índices regionales hacia adelante (forward) eran inferiores a la unidad. En otras palabras, se puede decir que, en 2004, este sector presentó encadenamientos hacia atrás por sobre el promedio de la economía de cada estado y un bajo nivel de efectos hacia adelante. Cabe resaltar la importancia de los encadenamientos hacia adelante de la industria paulista, que presentó un indicador hacia adelante de 0,87. Esta cifra muestra la relevancia del estado de São Paulo en la oferta de vehículos automotores.

Conviene destacar, sin embargo, que las relaciones de encadenamiento deben internalizarse en la región en

${ }^{6}$ La formalización de esos índices excede el ámbito de este artículo. Se puede encontrar más información sobre el tema en Ribeiro y otros (2010) o Ribeiro, Montenegro y Pereira (2013). que se sitúa la unidad industrial. Haddad y otros (2007) destacan, por ejemplo, que la planta de la compañía Fiat instalada en Minas Gerais en la década de 1970 dependía de insumos de fuera del estado, procedentes sobre todo de São Paulo. Sin embargo, en la década siguiente la empresa logró atraer a sus principales proveedores a Minas Gerais, un proceso que el autor denominó de "minerización" de Fiat. Ribeiro y Britto (2013), por su parte, señalan que la industria automotriz instalada en Bahia (Ford) aún no había obtenido este resultado, ya que dependía de insumos localizados fuera de las fronteras del estado. Esto representa un punto negativo, ya que esa característica tiende a generar salidas de empleo y renta.

Para evaluar el grado de esa internalización en cada uno de los estados analizados, en el cuadro 2 se presentan los resultados del multiplicador de producción 7 , desagregado en efectos intrarregionales e interregionales, como muestra el porcentaje de salidas de este indicador.

\footnotetext{
${ }^{7}$ Este indicador puede expresarse formalmente de esta manera: $M p_{j}=\sum_{i=1}^{n} b_{i j}$ Leontief.
}

CUADRO 1

Brasil (estados seleccionados): índices de eslabonamiento de Hirschman-Rasmussen de la industria automotriz, 2004

\begin{tabular}{|c|c|c|c|c|c|c|c|c|c|}
\hline Eslabonamientos & Bahia & Ceará & $\begin{array}{l}\text { Minas } \\
\text { Gerais }\end{array}$ & São Paulo & $\begin{array}{l}\text { Río de } \\
\text { Janeiro }\end{array}$ & Paraná & $\begin{array}{c}\text { Santa } \\
\text { Catarina }\end{array}$ & $\begin{array}{c}\text { Rio Grande } \\
\text { do Sul }\end{array}$ & Goiás \\
\hline Hacia atrás & 1,32 & 1,28 & 1,32 & 1,21 & 1,18 & 1,29 & 1,20 & 1,24 & 1,34 \\
\hline
\end{tabular}

Fuente: Elaboración propia sobre la base de J.J.M. Guilhoto y U.A. Sesso Filho, "Estimação da matriz insumo-produto a partir de dados preliminares das contas nacionais", Economia Aplicada, vol. 9, № 2, 2005; J.J.M. Guilhoto y otros, Matriz de insumo-produto do Nordeste e Estados: metodologia e resultados, Fortaleza, Banco do Nordeste, 2010.

CUADRO 2

Brasil (estados seleccionados): multiplicador de producción de la industria automotriz, 2004

\begin{tabular}{|c|c|c|c|c|c|c|c|c|c|}
\hline Efectos & Bahia & Ceará & $\begin{array}{l}\text { Minas } \\
\text { Gerais }\end{array}$ & São Paulo & $\begin{array}{l}\text { Río de } \\
\text { Janeiro }\end{array}$ & Paraná & $\begin{array}{c}\text { Santa } \\
\text { Catarina }\end{array}$ & $\begin{array}{l}\text { Rio Grande } \\
\text { do Sul }\end{array}$ & Goiás \\
\hline Intrarregionales & 1,48 & 1,69 & 1,66 & 1,83 & 1,65 & 1,41 & 1,65 & 1,87 & 1,45 \\
\hline Total & 2,52 & 2,41 & 2,54 & 2,28 & 2,17 & 2,46 & 2,32 & 2,36 & 2,61 \\
\hline $\begin{array}{l}\text { Salidas } \\
\text { (en porcentajes) }\end{array}$ & 41,3 & 30,0 & 34,9 & 19,7 & 23,8 & 42,6 & 28,9 & 20,8 & 44,4 \\
\hline
\end{tabular}

Fuente: Elaboración propia sobre la base de J.J.M. Guilhoto y U.A. Sesso Filho, "Estimação da matriz insumo-produto a partir de dados preliminares das contas nacionais", Economia Aplicada, vol. 9, № 2, 2005; J.J.M. Guilhoto y otros, Matriz de insumo-produto do Nordeste e Estados: metodologia e resultados, Fortaleza, Banco do Nordeste, 2010. 
El mayor multiplicador de producción total es el de la industria automotriz de Goiás. Esto quiere decir que, para atender cada variación de una unidad monetaria de la demanda de este sector, toda la economía tiene que producir 2,61 unidades. Sin embargo, ese mismo estado presenta el mayor efecto de salida, un $44 \%$, de manera que 1,16 unidades se generan en el resto del Brasil (efecto interregional) y solamente 1,45 se generan intrarregionalmente. En cambio, São Paulo presenta las menores salidas de producción: solo un 19,7\%. Esto puede deberse, en parte, a la consolidación de este segmento industrial en el estado, que es la sede de importantes ensambladoras.
Como era de esperar, el resultado de los multiplicadores de producción mostrados en el cuadro 2 refleja el origen de las compras del sector (véase el gráfico 2). Los estados con mayores multiplicadores interregionales (Goiás, Paraná y Bahia) y, en consecuencia, los que mostraron el mayor efecto de salida, son también los que más dependen de insumos con origen en el resto del Brasil. Este resultado indica que la industria automotriz de esos tres estados produce efectos interregionales sustanciales, lo que debería ser tomado en cuenta por políticas sectoriales cuyo objetivo sea generar un impacto a nivel nacional.

\section{IV}

\section{Distribución geográfica de la industria automotriz en el Brasil: un análisis por coeficientes de localización y coeficientes de asociación geográfica}

La mayoría de las empresas pertenecientes a la Asociación Nacional de Fabricantes de Vehículos Automotores (ANFAVEA) del Brasil mantienen sus principales unidades productivas en las regiones sudeste y sur, con la excepción de las fábricas de Ford y Mitsubishi, instaladas en el nordeste y centro-oeste, respectivamente. Al analizar la distribución geográfica de las principales unidades productivas, se constatan las características de aglomeración espacial en función de los efectos de las economías de aglomeración, mencionados en la sección II.

Antes del comienzo de la década de 1990, la industria automotriz estaba estancada. El plan de recuperación de dicha industria se manifestó en las medidas adoptadas en 1992 y 1993 en el ámbito de la Cámara Sectorial Automotriz. El gobierno, los trabajadores y el sector privado firmaron un acuerdo automotor, en el que se establecieron diversas metas para el sector.

De acuerdo con Santos y Burity (2003), a partir del nuevo régimen automotor, cambió la coyuntura de estancamiento y se anunciaron diversos planes de inversión. El régimen automotor tenía el objetivo de lograr la recuperación de las inversiones en el sector y generar ganancias de competitividad para incrementar las exportaciones. Este nuevo régimen se creó en $1995^{8}$ y se reformuló en 1997 para incluir los estados menos desarrollados. No solo comprendió incentivos fiscales para la instalación de empresas en el país, sino también incentivos diferenciados para las empresas que decidieran instalar unidades en regiones menos desarrolladas. Estas políticas motivaron que varias fábricas se instalaran en otros estados durante la tercera ola de inversiones en el sector, a partir de la segunda mitad de la década de 1990.

Marx y Mello (2008) subrayan que la industria automotriz ha sido objeto de muchos estudios y que diversas políticas públicas se han focalizado en ella. Esto se debe a su influencia elevada y directa en el producto interno bruto (PIB), así como a sus efectos indirectos, dada ante todo su capacidad de generar encadenamientos hacia atrás de la cadena productiva: vidrio, caucho, siderurgia, aluminio, petróleo, petroquímica, química, alcohol y biodiésel, bienes de capital y otros, además

\footnotetext{
${ }^{8}$ Según Rodríguez-Pose y Arbix (1999), desde 1996 se han adherido al nuevo régimen automotor 16 grandes ensambladoras, 150 empresas de autopartes y 29 empresas de otros sectores productivos.
} 
de los segmentos de servicios (encadenamientos hacia delante): comercio, seguros, oficinas, asistencia técnica y servicios técnicos especializados (ingeniería y diseño, entre otros), como puede verse en la sección III de este artículo.

A grandes rasgos, Marx y Mello (2008) destacan que el sector está formado por ensambladoras de automóviles, ensambladoras de camiones y chasis de autobuses y proveedores de repuestos y piezas, así como por un conjunto de segmentos heterogéneos. En ese sentido, la industria automotriz no puede resultar viable sin una fuerte implantación de los repuestos y partes.

Como se explica en Salerno y otros (2008), al igual que en Marx y Mello (2008), la industria automotriz se extiende más allá de la división económica de fabricación y ensamblaje de vehículos automotores, y también engloba actividades proveedoras de insumos básicos, que van desde el vidrio y el caucho hasta los servicios especializados. En el cuadro 3, se identifican las categorías de la Clasificación Nacional de Actividades Económicas (CNAE) utilizadas en este trabajo.

De acuerdo con Simões (2005, pág. 7), hay un conjunto de medidas descriptivas y de naturaleza eminentemente exploratoria para una primera aproximación a una gran masa de datos, que suelen utilizarse en diagnósticos para políticas de descentralización industrial y, principalmente, para la caracterización de patrones regionales de la distribución espacial de la actividad económica.

Estas medidas descriptivas se pueden dividir en medidas de localización y medidas de especialización. Las primeras, de naturaleza sectorial, se ocupan del patrón de localización de las actividades entre las regiones — Haddad (1989) — y procuran descubrir patrones de concentración o dispersión espacial. Las medidas de especialización, por su parte, se concentran en el análisis de la estructura productiva de cada región, con el objetivo de describir el grado de especialización regional y su diversificación en los diversos períodos.

Según la literatura, dentro de estas medidas de localización y especialización, las dos más utilizadas son el coeficiente de localización $\left(Q L_{i j}\right)$ y el coeficiente de asociación geográfica $\left(C A_{i k}\right)$.

El coeficiente de localización $\left(Q L_{i j}\right)^{9}$ indica la especialización relativa de un estado, en comparación con el grado de concentración de todos los estados productores seleccionados como representativos. Cuando el indicador es mayor que 1, significa que la participación relativa del sector en el estado es más elevada que la participación relativa del mismo sector en el promedio de todos los estados; y cuando es menor que 1 , no hay especialización productiva en el estado considerado. Autores como Combes (2000); Fochezatto (2010), y Freitas (2012)

\footnotetext{
${ }^{9}$ La fórmula del coeficiente de localización es la siguiente:$$
Q L_{i j}=\frac{E_{i j}}{\sum_{j} E_{i j}} / \frac{\sum_{i} E_{i j}}{\sum_{i} \sum_{j} E_{i j}}
$$

Donde: $\quad E_{i j}=$ Empleos en el sector $i$ del estado $j$. $\sum_{i} E_{i j}=$ Empleos en todos los sectores del estado $j$. $\sum_{j} E_{i j}=$ Empleos en el sector $i$ de todos los estados.

$\sum_{i} \sum_{j} E_{i j}=$ Empleos en todos los sectores de todos los estados.
} según la Clasificación Nacional de Actividades Económicas (CNAE) 1.0

\begin{tabular}{ll}
\hline Categoría & Descripción de la actividad \\
\hline Categoría 25 & Fabricación de artículos de caucho y plástico \\
Categoría 27 & Metalurgia básica \\
Categoría 26 & Fabricación de productos de minerales no metálicos \\
Categoría 29 & Fabricación de máquinas y equipamientos \\
Categoría 28 & Fabricación de productos de metal, excepto máquinas y equipamientos \\
Categoría 31 & Fabricación de maquinas, aparatos y materiales eléctricos \\
Categoría 34 & Fabricación y ensamblaje de vehículos automotores, remolques y carrocerías \\
Categoría 35 & Fabricación de otros equipamientos de transporte \\
Categoría 50 & Comercio y reparación de vehículos automotores y motocicletas; y comercio minorista de combustibles \\
Categoría 71 & Alquiler de vehículos, máquinas y equipamientos sin conductores ni operadores y de objetos personales y domésticos
\end{tabular}

Fuente: Instituto Brasileño de Geografía y Estadística (IBGE), Pesquisa Industrial Anual, 2010 [en línea] http://www.ibge.gov.br.

Nota: Cabe destacar que la categoría principal relacionada con la industria automotriz es la 34 (con las correspondientes clases de actividad de tres dígitos). Además, a excepción de la categoría 34, las demás categorías no incluyen clases de actividad económica exclusivas de la industria automovilística, ya que, en algunos casos, tienen vínculos más estrechos con otros sectores económicos, si bien también se vinculan con el sector automotor, desde la provisión de insumos básicos hasta los bienes intermedios con mayor valor agregado.

a En la CNAE 2.0 corresponde a la categoría 29. 
consideran, incluso, que ese indicador puede tomarse como variable representativa para la identificación de externalidades de tipo Marshall-Arrow-Romer (MAR).

De forma más específica, si los valores de QL se ubican entre 0 y 0,49 hay una localización débil, si están entre 0,50 y 0,99 existe una localización mediana y para valores mayores que 1 la localización es fuerte.

En los cuadros 4 a 9, se puede observar que el patrón de localización de la industria cambió significativamente a consecuencia de las inversiones realizadas en la década de 1990, lo que hizo que emergieran, a partir del año 2000, las actividades económicas en este sector industrial más allá de São Paulo (QL de 2,14) y Minas Gerais (QL de 1,10 ), como por ejemplo, en los estados de Paraná (QL de 0,47 , que denota una localización aún débil) y Rio Grande do Sul (QL de 0,93, es decir, una localización considerada mediana).

En 1995, se podía observar una localización productiva débil en los estados de Ceará, Bahia, Paraná y Goiás. El QL elevado de Santa Catarina puede deberse, en parte, a la industria automovilística centrada en la fabricación de camiones.

En el cuadro 5 se muestran los cálculos de QL para el año 2000, que reflejan la emergencia de nuevos polos especializados en este ramo industrial, más allá de São Paulo y Minas Gerais, localizados en los estados de Paraná ${ }^{10}$ y Rio Grande do Sul ${ }^{11}$.

\footnotetext{
${ }^{10}$ Según Rodríguez-Pose y Arbix (1999, pág. 66), “en marzo de 1996 el gobierno del estado, el municipio de São José dos Pinhais y el Fondo de Desarrollo Económico firmaron un protocolo con Renault. Las condiciones del acuerdo establecían que Renault debía construir una planta en São José dos Pinhais hasta comienzos de 1999 y que el $60 \%$ del capital total del proyecto correspondería a la multinacional francesa, la que, además, crearía 1.500 empleos directos y pagaría una penalización de 50,5 millones de reales si la planta se desactivara antes de 20 años. El estado de Paraná y el municipio de São José dos Pinhais donarían 2,5 millones de metros cuadrados y proporcionarían la infraestructura y la logística necesarias, incluidos los accesos ferroviarios y por carretera, así como un área exclusiva para la empresa en el puerto de Paranaguá. El suministro de energía se realizaría a una tasa de un $25 \%$ inferior a la de mercado. Correspondería al estado el $40 \%$ del capital invertido (con un máximo de 300 millones de dólares). Los préstamos oficiales a Renault estarían vinculados a los niveles de producción de la empresa, no tendrían corrección inflacionaria y comenzarían a pagarse 10 años después de iniciado el funcionamiento. Además, Renault quedaría exenta de impuestos locales durante 10 años, al igual que todos los proveedores que acudieran a instalarse en la misma zona, la cual, dicho sea de paso, es de protección ambiental".

${ }^{11}$ Según Rodríguez-Pose y Arbix (1999, pág. 67), "las condiciones del acuerdo de General Motors con el Gobierno de Rio Grande do Sul también fueron extremadamente generosas para la ensambladora. El protocolo firmado preveía 310 millones de dólares en préstamos oficiales destinados a financiar la compra del terreno, a una tasa de interés del 6\% anual y pagaderos a partir de 2002. La exención de impuestos duraría 15 años y, además, el estado debía proporcionar infraestructura y los servicios de agua, electricidad, gas natural y
}

Entre 1989 y 2003, la industria automotriz experimentó la primera reestructuración productiva $y$, desde 2004 hasta 2010, se produjo una segunda etapa de consolidación del país como centro consumidor y plataforma regional de producción y distribución de vehículos, según Costa y Henkin (2011, pág. 12). Asimismo, según estos autores, las nuevas empresas del sector comienzan a invertir en la instalación de producción nacional. Las ensambladoras "tradicionales" están siguiendo un curso similar, mediante el establecimiento de nuevas unidades productivas en el país y la modernización de las ya existentes, con el objetivo de mantener sus posiciones en el mercado, amenazadas por las nuevas ensambladoras. Ese proceso hizo que el QL de Rio Grande do Sul en 2000 (QL de 1,19) fuera superior incluso a la especialización productiva de Minas Gerais (QL de 1,12).

En CNi/CEPAL (2001) se indica que, desde 1996, ya podía observarse una tendencia a la intensificación de la diversificación espacial de las inversiones en las industrias. Los beneficios fiscales de los estados, la proximidad del mercado consumidor y el costo de la mano de obra fueron los principales factores determinantes de este proceso (véase el cuadro 6).

En ese contexto, como denota el patrón de las instalaciones de fábricas del cuadro 4 , los efectos de economías de aglomeración y de los beneficios fiscales del sector público tuvieron una gran influencia en la localización industrial de las ensambladoras fuera de la zona tradicional formada por los estados de São Paulo y Minas Gerais, en el período analizado.

Por otra parte, como se destaca en Rodríguez-Pose y Arbix (1999, pág. 64), las diferencias salariales en el interior del Brasil y las mejoras de la educación en el país en los últimos años han hecho que las ensambladoras busquen las regiones con menores costos laborales. En ese sentido, los trabajadores del estado de São Paulo, en particular de la región metropolitana del estado, se encuentran en situación de desventaja en relación con los del resto del país en cuanto al costo por hora de trabajo.

Según Rodríguez-Pose y Arbix (1999, pág. 69), después de que los fabricantes escojan al Brasil como el lugar adecuado para sus inversiones, los estados que compiten por atraer las ensambladoras financian, de hecho, gran parte de las instalaciones y del propio funcionamiento de las nuevas fábricas. Tras la implantación del régimen automotor especial, varias ensambladoras

telecomunicaciones a tasas subsidiadas. Además, debía construir un puerto privado y un canal marítimo de acceso, así como garantizar el transporte público hasta la fábrica". 


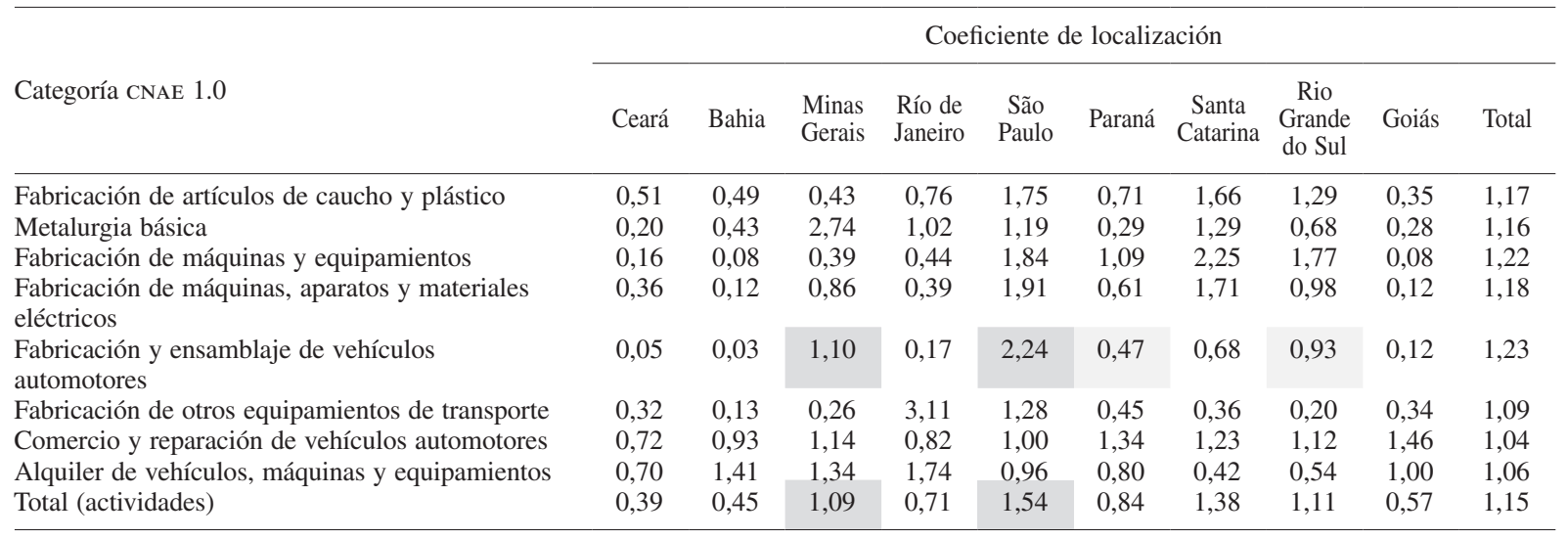

Fuente: Elaboración propia sobre la base de Ministerio del Trabajo y Empleo, Relação Anual de Informações Sociais, Brasilia, 2006.

CUADRO 5

\begin{abstract}
Brasil (estados seleccionados): coeficientes de localización por categorías de la Clasificación Nacional de Actividades Económicas (CNAE) 1.0 de actividades relacionadas con la industria automotriz, 2000
\end{abstract}

\begin{tabular}{|c|c|c|c|c|c|c|c|c|c|c|}
\hline \multirow[b]{2}{*}{ Categoría CNAE 1.0} & \multicolumn{10}{|c|}{ Coeficiente de localización } \\
\hline & Ceará & Bahia & $\begin{array}{l}\text { Minas } \\
\text { Gerais }\end{array}$ & $\begin{array}{l}\text { Río de } \\
\text { Janeiro }\end{array}$ & $\begin{array}{c}\text { São } \\
\text { Paulo }\end{array}$ & Paraná & $\begin{array}{c}\text { Santa } \\
\text { Catarina }\end{array}$ & $\begin{array}{c}\text { Rio } \\
\text { Grande } \\
\text { do Sul }\end{array}$ & Goiás & Total \\
\hline Fabricación de artículos de caucho y plástico & 0,48 & 0,48 & 0,53 & 0,66 & 1,68 & 0,90 & 1,97 & 1,53 & 0,43 & 1,18 \\
\hline Metalurgia básica & 0,18 & 0,42 & 2,74 & 0,96 & 1,11 & 0,33 & 1,67 & 0,71 & 0,39 & 1,15 \\
\hline Fabricación de máquinas y equipamientos & 0,31 & 0,12 & 0,48 & 0,41 & 1,81 & 1,17 & 2,13 & 1,90 & 0,21 & 1,22 \\
\hline $\begin{array}{l}\text { Fabricación de máquinas, aparatos y materiales } \\
\text { eléctricos }\end{array}$ & 0,40 & 0,15 & 0,87 & 0,35 & 1,89 & 0,96 & 1,76 & 1,03 & 0,20 & 1,19 \\
\hline $\begin{array}{l}\text { Fabricación y ensamblaje de vehículos } \\
\text { automotores }\end{array}$ & 0,14 & 0,09 & 1,12 & 0,21 & 2,06 & 1,23 & 0,71 & 1,19 & 0,19 & 1,24 \\
\hline $\begin{array}{l}\text { Fabricación de otros equipamientos de } \\
\text { transporte }\end{array}$ & 0,25 & 0,25 & 0,51 & 1,04 & 1,85 & 0,39 & 0,49 & 0,26 & 0,44 & 1,04 \\
\hline Comercio y reparación de vehículos automotores & 0,74 & 0,94 & 1,14 & 0,80 & 0,95 & 1,22 & 1,24 & 1,02 & 1,39 & 1,01 \\
\hline $\begin{array}{l}\text { Alquiler de vehículos, máquinas y } \\
\text { equipamientos }\end{array}$ & 1,16 & 1,66 & 1,33 & 1,57 & 0,91 & 0,88 & 0,48 & 0,51 & 0,83 & 1,04 \\
\hline Total (actividades) & 0,48 & 0,54 & 1,09 & 0,65 & 1,43 & 1,04 & 1,44 & 1,18 & 0,70 & 1,12 \\
\hline
\end{tabular}

Fuente: Elaboración propia sobre la base de Ministerio del Trabajo y Empleo, Relação Anual de Informações Sociais, Brasilia, 2006.

que habían anunciado inversiones en zonas próximas a São Paulo cambiaron la localización de sus plantas a las regiones nordeste, norte y centro-oeste.

Con respecto al sector automotor en particular, Latini (2007) y Santos y Burity (2003) señalan que las principales medidas que incentivaron al sector entre 1989 y 1993 fueron la creación de la Cámara Sectorial de la Industria Automotriz en 1992, los acuerdos automotores de 1992 y 1993 y el Decreto 799/1993, que establecía incentivos para la fabricación de vehículos de baja cilindrada.
Santos y Burity (2003) indican que, entre 1990 y 1998, se aprobaron 21 instrumentos (entre normas administrativas, decretos y medidas provisorias) relativos a la reducción de tasas impositivas: el impuesto sobre la circulación de mercancías y servicios (ICMS) y el impuesto sobre los productos industrializados (IPI) en la época de la Cámara Sectorial, además de los acuerdos de emergencias y del régimen automotor. También durante los años noventa se produjeron las reducciones de las tasas de importación y de los índices de nacionalización exigidos para la industria, que cayeron del $85 \%$ al $60 \%$. 
Brasil (estados seleccionados): factores que influyeron favorablemente en la instalación de plantas en otros lugares, 1998-2002

(En porcentajes)

\begin{tabular}{|c|c|c|c|c|c|c|}
\hline \multirow[b]{2}{*}{ Factores principales } & \multicolumn{3}{|c|}{ 1998-1999 } & \multicolumn{3}{|c|}{ 2000-2002 } \\
\hline & $\begin{array}{c}\text { En otro } \\
\text { estado }\end{array}$ & $\begin{array}{c}\text { Dentro del } \\
\text { estado }\end{array}$ & Total & $\begin{array}{l}\text { En otro } \\
\text { estado }\end{array}$ & $\begin{array}{l}\text { Dentro del } \\
\text { estado }\end{array}$ & Total \\
\hline Costo de la mano de obra & 40,9 & 38,9 & 44,2 & 39 & 47,4 & 86 \\
\hline Calificación de la mano de obra & 9,1 & 27,8 & 20,9 & 7,3 & 15,8 & 23,3 \\
\hline Beneficios fiscales federales & 13,6 & 5,6 & 14 & 22 & 2,6 & 23,3 \\
\hline Beneficios fiscales estatales & 54,5 & 22,2 & 41,9 & 56,1 & 23,7 & 83,7 \\
\hline Beneficios municipales & 18,2 & 22,2 & 23,3 & 34,1 & 50 & 83,7 \\
\hline Sindicato en activo en la región de origen & - & 16,7 & 9,3 & 2,4 & 7,9 & 14 \\
\hline Saturación espacial en la región de origen & 27,3 & 27,8 & 25,6 & 12,2 & 31,6 & 39,5 \\
\hline Proximidad a materias primas y recursos naturales & 13,6 & 27,8 & 20,9 & 29,3 & 21,1 & 51,2 \\
\hline Proximidad del mercado consumidor & 50 & 27,8 & 41,9 & 56,1 & 26,3 & 86 \\
\hline Mejor infraestructura & 13,6 & 33,3 & 25,6 & 4,9 & 31,6 & 34,9 \\
\hline
\end{tabular}

Fuente: Confederación Nacional de la Industria (CNI)/Comisión Económica para América Latina y el Caribe (CEPAL), Investimentos na Indústria Brasileira 1998-2002, Brasilia, 2001.

Este nuevo patrón de localización asumido por la industria automotriz no se modificó durante la primera década del siglo XxI. Se puede observar en los cuadros 7 a 9 que los principales polos especializados de este sector industrial siguieron siendo los estados de São Paulo, Minas Gerais, Paraná y Rio Grande do Sul.

Este resultado puede vincularse con los índices de insumo-producto calculados en la sección anterior. La industria automotriz de esos estados mostró indicadores de encadenamientos hacia atrás por sobre el promedio. Además, la mayor parte de las materias primas de este segmento se produjeron en los respectivos estados. Por tanto, es de esperar que el sector presente un QL elevado, tanto en lo referente al propio sector de ensamblaje de vehículos como a las actividades que proveen los insumos. De hecho, se observó una correlación entre los estados con mayor tasa de autosuficiencia de insumos y los que registraron un QL más elevado, es decir, Rio grande do Sul (70,3\%) y São Paulo (63,8\%).

Como ya se ha señalado, el índice de encadenamiento hacia atrás de la industria automotriz de Bahia sobrepasa el promedio. Sin embargo, más de la mitad de los insumos de este sector provienen de fuera del estado, lo que se muestra tanto en el análisis de insumo-producto como por los resultados del QL (véase el cuadro 7), que indican una baja concentración de industrias hacia atrás. De esta forma, en un primer momento, para aumentar la competitividad de este segmento deben crearse mecanismos de atracción de industrias proveedoras de insumos hacia la misma zona. Esto daría lugar a una expansión de la concentración de industrias proveedoras de materias primas para el sector automotor de Bahia, lo que tendería a reflejarse en un QL más alto. El resultado de Ceará es más preocupante, ya que el sector automotor en este estado posee encadenamientos hacia atrás por sobre el promedio $(1,28)$ y registró el tercer mayor índice de autosuficiencia $(63,1 \%)$ de los estados analizados. Aun así, esa autosuficiencia relativamente elevada no parece bastar para que el estado incremente su competitividad. El dato más significativo entre 2006 y 2009 es la reducción del QL de São Paulo y el gran aumento de Minas Gerais. Según Rodríguez-Pose y Arbix (1999, págs. 66-67), "Mercedes-Benz anunció a continuación una inversión de 400 millones de dólares, con la creación de 1.500 empleos directos, para la instalación de una nueva planta en Juiz de Fora. La ensambladora alemana recibiría préstamos oficiales por valor de 100 millones de dólares y exención de impuestos estatales y municipales durante 10 años, así como un terreno de 2,8 millones de metros cuadrados, infraestructura y urbanización de los márgenes del río Paraibuna, construcción de vías de acceso, estacionamientos, pista de pruebas, desarrollo de infraestructura sanitaria, una terminal ferroviaria y pequeñas mejoras, como escuelas para los hijos de los trabajadores. Además, la ensambladora recibió garantías del estado en cuanto al establecimiento de una normativa ambiental más rígida, a fin de dificultar que otras empresas desarrollaran en el entorno de la planta actividades consideradas como perjudiciales para la producción de vehículos".

Se puede observar que durante el período, el coeficiente de localización de la suma de las actividades creció en los estados de Paraná y Rio Grande do Sul en detrimento de Minas Gerais y São Paulo. Esto significa que 


\begin{tabular}{|c|c|c|c|c|c|c|c|c|c|c|}
\hline \multirow[b]{2}{*}{ Categoría CNAE 1.0} & \multicolumn{10}{|c|}{ Coeficiente de localización } \\
\hline & Ceará & Bahia & $\begin{array}{l}\text { Minas } \\
\text { Gerais }\end{array}$ & $\begin{array}{l}\text { Río de } \\
\text { Janeiro }\end{array}$ & $\begin{array}{l}\text { São } \\
\text { Paulo }\end{array}$ & Paraná & $\begin{array}{c}\text { Santa } \\
\text { Catarina }\end{array}$ & $\begin{array}{c}\text { Rio } \\
\text { Grande } \\
\text { do Sul }\end{array}$ & Goiás & Total \\
\hline Fabricación de artículos de caucho y plástico & 0,52 & 0,65 & 0,61 & 0,56 & 1,62 & 1,01 & 1,97 & 1,46 & 0,49 & 1,17 \\
\hline Metalurgia básica & 0,38 & 0,33 & 2,73 & 0,86 & 1,14 & 0,40 & 1,63 & 0,85 & 0,23 & 1,16 \\
\hline Fabricación de máquinas y equipamientos & 0,30 & 0,31 & 0,66 & 0,49 & 1,73 & 1,09 & 2,10 & 1,90 & 0,23 & 1,22 \\
\hline $\begin{array}{l}\text { Fabricación y ensamblaje de vehículos } \\
\text { automotores }\end{array}$ & 0,15 & 0,41 & 1,01 & 0,27 & 2,04 & 1,30 & 0,64 & 1,51 & 0,24 & 1,26 \\
\hline $\begin{array}{l}\text { Fabricación de otros equipamientos de } \\
\text { transporte }\end{array}$ & 0,34 & 0,11 & 0,30 & 2,99 & 1,30 & 0,28 & 0,75 & 0,58 & 0,14 & 1,04 \\
\hline Comercio y reparación de vehículos automotores & 0,77 & 0,90 & 1,10 & 0,75 & 0,96 & 1,24 & 1,30 & 1,02 & 1,24 & 1,00 \\
\hline $\begin{array}{l}\text { Alquiler de vehículos, máquinas y } \\
\text { equipamientos }\end{array}$ & 0,99 & 1,35 & 1,24 & 1,44 & 1,03 & 0,73 & 0,62 & 0,50 & 0,67 & 1,02 \\
\hline Total (actividades) & 0,52 & 0,62 & 1,08 & 0,69 & 1,40 & 1,06 & 1,45 & 1,23 & 0,64 & 1,12 \\
\hline
\end{tabular}

Fuente: Elaboración propia sobre la base de Ministerio del Trabajo y Empleo, Relação Anual de Informações Sociais, Brasilia, 2006.

CUADRO 8

\begin{abstract}
Brasil (estados seleccionados): coeficientes de localización por categorías de la Clasificación Nacional de Actividades Económicas (CNAE) 1.0 de actividades relacionadas con la industria automotriz, 2009
\end{abstract}

\begin{tabular}{|c|c|c|c|c|c|c|c|c|c|c|}
\hline \multirow[b]{2}{*}{ Categoría CNAE 1.0} & \multicolumn{10}{|c|}{ Coeficiente de localización } \\
\hline & Ceará & Bahia & $\begin{array}{l}\text { Minas } \\
\text { Gerais }\end{array}$ & $\begin{array}{l}\text { Río de } \\
\text { Janeiro }\end{array}$ & $\begin{array}{l}\text { São } \\
\text { Paulo }\end{array}$ & Paraná & $\begin{array}{c}\text { Santa } \\
\text { Catarina }\end{array}$ & $\begin{array}{c}\text { Rio } \\
\text { Grande } \\
\text { do Sul }\end{array}$ & Goiás & Total \\
\hline Fabricación de artículos de caucho y plástico & 0,43 & 0,67 & 0,64 & 0,60 & 1,62 & 1,04 & 1,96 & 1,41 & 0,49 & 1,17 \\
\hline Metalurgia básica & 0,50 & 0,39 & 2,65 & 0,95 & 1,12 & 0,44 & 1,62 & 0,91 & 0,23 & 1,16 \\
\hline Fabricación de máquinas y equipamientos & 0,24 & 0,37 & 0,60 & 0,56 & 1,67 & 1,14 & 2,14 & 2,12 & 0,31 & 1,22 \\
\hline $\begin{array}{l}\text { Fabricación de máquinas, aparatos y materiales } \\
\text { eléctricos }\end{array}$ & 0,35 & 0,32 & 1,20 & 0,21 & 1,71 & 1,37 & 2,16 & 0,96 & 0,11 & 1,19 \\
\hline $\begin{array}{l}\text { Fabricación y ensamblaje de vehículos } \\
\text { automotores }\end{array}$ & 0,15 & 0,36 & 1,20 & 0,30 & 1,97 & 1,29 & 0,69 & 1,59 & 0,35 & 1,27 \\
\hline $\begin{array}{l}\text { Fabricación de otros equipamientos de } \\
\text { transporte }\end{array}$ & 0,41 & 0,09 & 0,16 & 2,94 & 1,15 & 0,42 & 0,89 & 0,47 & 0,14 & 0,96 \\
\hline Comercio y reparación de vehículos automotores & 0,76 & 0,94 & 1,09 & 0,72 & 0,93 & 1,24 & 1,31 & 1,06 & 1,27 & 0,99 \\
\hline $\begin{array}{l}\text { Alquiler de vehículos, máquinas y } \\
\text { equipamientos }\end{array}$ & 0,96 & 1,21 & 1,38 & 1,25 & 1,02 & 0,76 & 0,55 & 0,52 & 0,78 & 1,01 \\
\hline Total (actividades) & 0,51 & 0,65 & 1,08 & 0,71 & 1,34 & 1,10 & 1,46 & 1,28 & 0,69 & 1,11 \\
\hline
\end{tabular}

Fuente: Elaboración propia sobre la base de Ministerio del Trabajo y Empleo, Relação Anual de Informações Sociais, Brasilia, 2006.

la industria automotriz, además de haber experimentado una desconcentración, se volvió menos heterogénea entre los cuatro principales estados productores en 2011.

A pesar de esta leve desconcentración en el período más reciente, se puede observar el nivel de importancia relativa de la industria automotriz a partir de la distribución espacial del empleo correspondiente a la fabricación y ensamblaje de vehículos automotores, remolques y carrocerías en términos de clase de actividad económica (véase el cuadro 10). São Paulo concentra casi el $56 \%$ de todas las clases de actividades económicas relacionadas. 
CUADRO 9

Brasil (estados seleccionados): coeficientes de localización por categorías de la Clasificación Nacional de Actividades Económicas (CNAE) 1.0 de actividades relacionadas con la industria automotriz, 2011

\begin{tabular}{|c|c|c|c|c|c|c|c|c|c|c|}
\hline \multirow[b]{2}{*}{ Categoría CNAE 1.0} & \multicolumn{10}{|c|}{ Coeficiente de localización } \\
\hline & Ceará & Bahia & $\begin{array}{l}\text { Minas } \\
\text { Gerais }\end{array}$ & $\begin{array}{l}\text { Río de } \\
\text { Janeiro }\end{array}$ & $\begin{array}{l}\text { São } \\
\text { Paulo }\end{array}$ & Paraná & $\begin{array}{c}\text { Santa } \\
\text { Catarina }\end{array}$ & $\begin{array}{c}\text { Rio } \\
\text { Grande } \\
\text { do Sul }\end{array}$ & Goiás & Total \\
\hline Fabricación de artículos de caucho y plástico & 0,41 & 0,73 & 0,66 & 0,64 & 1,59 & 1,08 & 1,96 & 1,46 & 0,48 & 1,17 \\
\hline Metalurgia básica & 0,45 & 0,37 & 2,61 & 1,00 & 1,11 & 0,57 & 1,87 & 0,86 & 0,22 & 1,17 \\
\hline Fabricación de máquinas y equipamientos & 0,25 & 0,31 & 0,68 & 0,54 & 1,62 & 1,20 & 2,15 & 2,15 & 0,38 & 1,21 \\
\hline $\begin{array}{l}\text { Fabricación de máquinas, aparatos y materiales } \\
\text { eléctricos }\end{array}$ & 0,36 & 0,37 & 1,02 & 0,23 & 1,67 & 1,61 & 2,43 & 1,00 & 0,17 & 1,20 \\
\hline $\begin{array}{l}\text { Fabricación y ensamblaje de vehículos } \\
\text { automotores }\end{array}$ & 0,17 & 0,31 & 1,34 & 0,34 & 1,88 & 1,36 & 0,60 & 1,73 & 0,41 & 1,26 \\
\hline $\begin{array}{l}\text { Fabricación de otros equipamientos de } \\
\text { transporte }\end{array}$ & 0,46 & 0,23 & 0,22 & 2,82 & 1,11 & 0,26 & 1,19 & 0,72 & 0,15 & 0,98 \\
\hline Comercio y reparación de vehículos automotores & 0,81 & 0,96 & 1,08 & 0,69 & 0,93 & 1,24 & 1,30 & 1,08 & 1,29 & 0,99 \\
\hline $\begin{array}{l}\text { Alquiler de vehículos, máquinas y } \\
\text { equipamientos }\end{array}$ & 0,88 & 1,16 & 1,31 & 1,77 & 0,90 & 0,77 & 0,54 & 0,53 & 0,69 & 1,01 \\
\hline Total (actividades) & 0,52 & 0,65 & 1,10 & 0,73 & 1,31 & 1,15 & 1,48 & 1,32 & 0,72 & 1,11 \\
\hline
\end{tabular}

Fuente: Elaboración propia sobre la base de Ministerio del Trabajo y Empleo, Relação Anual de Informações Sociais, Brasilia, 2006.

CUADRO 10

Brasil (estados seleccionados): distribución de la mano de obra formal en la fabricación y ensamblaje de vehículos automotores, remolques y carrocerías, 2011 (En porcentajes)

\begin{tabular}{|c|c|c|c|c|c|c|c|c|c|c|}
\hline Clase de actividad económica & Ceará & Bahia & $\begin{array}{l}\text { Minas } \\
\text { Gerais }\end{array}$ & $\begin{array}{l}\text { Río de } \\
\text { Janeiro }\end{array}$ & $\begin{array}{l}\text { São } \\
\text { Paulo }\end{array}$ & Paraná & $\begin{array}{c}\text { Santa } \\
\text { Catarina }\end{array}$ & $\begin{array}{l}\text { Rio } \\
\text { Grande } \\
\text { do Sul }\end{array}$ & Goiás & Total \\
\hline $\begin{array}{l}\text { Fabricación de automóviles, } \\
\text { furgonetas y utilitarios }\end{array}$ & 0,51 & 3,80 & 17,09 & 4,69 & 54,81 & 10,42 & 0,03 & 4,18 & 4,46 & 100 \\
\hline Fabricación de camiones y autobuses & 0,00 & 0,00 & 0,00 & 3,64 & 73,29 & 13,98 & 0,00 & 9,09 & 0,00 & 100 \\
\hline $\begin{array}{l}\text { Fabricación de cabinas, carrocerías y remolques } \\
\text { para camiones }\end{array}$ & 1,64 & 1,56 & 4,43 & 5,73 & 30,10 & 14,64 & 11,06 & 29,36 & 1,48 & 100 \\
\hline Fabricación de carrocerías para autobuses & 0,09 & 0,00 & 0,13 & 12,00 & 18,50 & 7,69 & 8,53 & 53,05 & 0,00 & 100 \\
\hline $\begin{array}{l}\text { Fabricación de cabinas, carrocerías y remolques } \\
\text { para otros vehículos }\end{array}$ & 3,06 & 1,38 & 35,93 & 3,22 & 26,50 & 10,30 & 2,73 & 8,29 & 8,59 & 100 \\
\hline $\begin{array}{l}\text { Fabricación de partes y accesorios para el } \\
\text { sistema motor }\end{array}$ & 0,00 & 0,93 & 10,93 & 1,21 & 66,19 & 11,77 & 6,36 & 2,27 & 0,34 & 100 \\
\hline $\begin{array}{l}\text { Fabricación de partes y accesorios para los } \\
\text { sistemas de marcha y transmisión }\end{array}$ & 0,00 & 0,02 & 3,20 & 0,12 & 76,53 & 0,19 & 0,05 & 19,88 & 0,00 & 100 \\
\hline $\begin{array}{l}\text { Fabricación de partes y accesorios para el } \\
\text { sistema de frenado }\end{array}$ & 3,50 & 0,35 & 8,57 & 2,36 & 54,16 & 1,45 & 4,47 & 25,14 & 0,00 & 100 \\
\hline $\begin{array}{l}\text { Fabricación de partes y accesorios para el } \\
\text { sistema de dirección y suspensión }\end{array}$ & 1,27 & 0,03 & 13,72 & 6,95 & 59,56 & 8,39 & 2,63 & 7,23 & 0,21 & 100 \\
\hline $\begin{array}{l}\text { Fabricación de otras partes y accesorios } \\
\text { para vehículos automotores no especificados } \\
\text { anteriormente }\end{array}$ & 0,10 & 1,30 & 19,85 & 1,40 & 60,84 & 7,05 & 1,41 & 7,95 & 0,10 & 100 \\
\hline $\begin{array}{l}\text { Reparación o recuperación de motores para } \\
\text { vehículos automotores }\end{array}$ & 4,37 & 4,29 & 19,37 & 7,84 & 34,29 & 9,70 & 8,51 & 6,58 & 5,06 & 100 \\
\hline Total & 0,53 & 1,57 & 14,50 & 3,30 & 56,04 & 8,84 & 2,75 & 11,21 & 1,25 & 100 \\
\hline
\end{tabular}

Fuente: Elaboración propia sobre la base de Ministerio del Trabajo y Empleo, Relação Anual de Informações Sociais, Brasilia, 2006. 


\section{Asociación geográfica de la distribución de la industria automotriz en el Brasil en relación con la fabricación y el ensamblaje de vehículos}

El coeficiente de asociación geográfica $\left(C A_{i k}\right)^{12}$ muestra la asociación de tipo geográfico entre dos sectores (denominados $i$ y $k$ ), comparando las distribuciones porcentuales de la mano de obra entre los estados productores. Sus valores varían entre 0 -que significa que el sector $i$ está distribuido entre los estados de la misma forma que el sector $k$ (de modo que se puede concluir que los patrones de localización de ambos sectores están asociados geográficamente) — hasta valores próximos a 1, que indican que no existe ninguna asociación.

En concreto, se considera que los valores entre 0 y 0,35 manifiestan una asociación significativa, los valores entre 0,36 y 0,68 una asociación mediana y los valores superiores o iguales a 0,69 una asociación débil.

En el análisis del cuadro 11 se observa que los sectores relacionados con la fabricación y el ensamblaje de vehículos automotores muestran una importante asociación, la que decrece ligeramente a lo largo del tiempo, pero se mantiene en un nivel altamente significativo. Entre los que presentan una mayor asociación se destacan la fabricación de máquinas, aparatos y materiales eléctricos, la fabricación de máquinas y equipamientos y la fabricación de artículos de caucho

\footnotetext{
${ }^{12}$ La fórmula del coeficiente de asociación geográfica es: Sector $i \quad$ Sector $k$$$
C A_{i k}=\frac{\sum_{j}\left(\left|\left(E_{i j} / \sum_{i} E_{i j}\right)-\left(E_{i j} / \sum_{i} E_{i j}\right)\right|\right)}{2}
$$$$
\text { donde: } \quad E_{i j}=\text { Empleos en el sector } i \text { del estado } j \text {. }
$$$$
\sum_{i} E_{i j}=\text { Empleos en todos los sectores del estado } j \text {. }
$$

y plástico, lo que indica que la industria nacional de vehículos automotores tiene un proceso productivo bastante integrado, de manera que los patrones de localización de estos sectores están asociados geográficamente. Como se puede ver en los cuadros 7 a 9, el aumento del QL de la fabricación de vehículos automotores en los estados se vio acompañado de una buena parte de las actividades destacadas, lo que demuestra la enorme capacidad de arrastre de esta industria, lo que, una vez más, también puede relacionarse con índices de encadenamiento de Hirschman-Rasmussen por sobre el promedio.

Según los resultados conjuntos, obtenidos a partir del cálculo de las medidas de localización y especialización, se observa que la tercera ola de inversiones iniciada en la segunda mitad de la década de 1990 logró producir, de hecho, una ligera desconcentración espacial de la industria automotriz nacional, a través de la expansión desde los polos tradicionales de São Paulo y Minas Gerais, como también se puede apreciar en el cuadro 12 en términos del valor de la transformación industrial (VTI).

Es necesario resaltar que no todas las inversiones realizadas desde la década de 1990 fueron significativas en el sentido de contribuir a la desconcentración espacial de la industria, como fue el caso de las realizadas en Paraná y en Rio Grande do Sul. Las inversiones destinadas a Río de Janeiro, Bahia y Goiás, aunque hayan logrado hacer crecer los respectivos coeficientes de localización, no produjeron el mismo efecto estadístico registrado en los dos estados mencionados de la región Sur.

La principal hipótesis sobre esta discrepancia se relaciona con el hecho de que las empresas que se trasladaron a Río de Janeiro, Bahia y Goiás, en concreto Ford, Peugeot/Citroën, Mitsubishi y Hyundai, no son las compañías líderes del mercado brasileño, ni las que más crecieron en el período, a diferencia de las que optaron por localizarse en Paraná y Rio Grande do Sul: Volkswagen, General Motors y Renault/Nissan.

CUADRO 11

Brasil: coeficientes de asociación geográfica de la fabricación y ensamblaje de vehículos automotores en relación con los sectores complementarios, 1995-2011

\begin{tabular}{|c|c|c|c|c|c|}
\hline Categorías CNAE 1.0 & 1995 & 2000 & 2006 & 2009 & 2011 \\
\hline Fabricación de artículos de caucho y plástico & 0,20 & 0,17 & 0,14 & 0,13 & 0,14 \\
\hline Metalurgia básica & 0,35 & 0,36 & 0,34 & 0,32 & 0,31 \\
\hline Fabricación de máquinas y equipamientos & 0,20 & 0,14 & 0,13 & 0,14 & 0,13 \\
\hline Fabricación de máquinas, aparatos y materiales eléctricos & 0,10 & 0,07 & 0,09 & 0,10 & 0,12 \\
\hline Fabricación y ensamblaje de vehículos automotores & - & - & - & - & - \\
\hline Fabricación de otros equipamientos de transporte & 0,41 & 0,18 & 0,35 & 0,37 & 0,37 \\
\hline Comercio y reparación de vehículos automotores & 0,35 & 0,28 & 0,27 & 0,25 & 0,23 \\
\hline Alquiler de vehículos, máquinas y equipamientos & 0,40 & 0,37 & 0,32 & 0,29 & 0,32 \\
\hline
\end{tabular}

Fuente: Elaboración propia sobre la base de Ministerio del Trabajo y Empleo, Relação Anual de Informações Sociais, Brasilia, 2006. 
(En porcentajes)

\begin{tabular}{|c|c|c|c|c|c|c|c|c|c|c|c|c|c|c|c|}
\hline Estado & 1996 & 1997 & 1998 & 1999 & 2000 & 2001 & 2002 & 2003 & 2004 & 2005 & 2006 & $2007^{\mathrm{a}}$ & 2008 & 2009 & 2010 \\
\hline Brasil & 7,87 & 8,4 & 7,96 & 6,1 & 6,95 & 6,55 & 7,07 & 7,48 & 7,73 & 7,77 & 8,03 & 9,29 & 9,81 & 10,1 & 10,1 \\
\hline Minas Gerais & 12,5 & 13,93 & 11,07 & 9,27 & 11,2 & 10,37 & 9,09 & 9,42 & 8,93 & 9,51 & 11,47 & 13,4 & 13,6 & 13,4 & 11,87 \\
\hline Río de Janeiro & 0,98 & 1,13 & 3,91 & 2,85 & 2,93 & 3,49 & 3,61 & 3,4 & 4,15 & 4,71 & 4,27 & 4,61 & 5,13 & 4,33 & 5,05 \\
\hline São Paulo & 11,83 & 12,14 & 11,49 & 8,22 & 9,45 & 8,77 & 9,65 & 10,6 & 11,1 & 10,98 & 11,16 & 12,9 & 13,4 & 14,3 & 15,06 \\
\hline Paraná & 3,33 & 4,01 & 5,49 & 8,46 & 10,7 & 7,89 & 11,6 & 10,8 & 12,5 & 11,31 & 11,73 & 13,1 & 14,9 & 16,3 & 15,96 \\
\hline Rio Grande do Sul & 5,45 & 6,4 & 5,12 & 4,93 & 5,98 & 7,59 & 6,98 & 8,21 & 7,77 & 7,93 & 8,42 & 9,74 & 10,3 & 11,8 & 12,04 \\
\hline Santa Catarina & 3,88 & 4,24 & 3,96 & 4,22 & 4,62 & 4,62 & 3,44 & 3,53 & 3,81 & 4,53 & 4,59 & 4,55 & 5,26 & 3,47 & 3,71 \\
\hline Ceará & 0,59 & 0,75 & 0,72 & 0,66 & 0,53 & 0,92 & 1,02 & 0,78 & 1,22 & 1,22 & 0,85 & 0,96 & 0,93 & 0,78 & 0,83 \\
\hline Bahia & 0,08 & 0,09 & 0,04 & 0,04 & 0,03 & 0,04 & 4,13 & 5,79 & 5,6 & 6,31 & 6,19 & 6,39 & 9,27 & 10,3 & 9,71 \\
\hline Goiás & 0,29 & 0,43 & 0,34 & 0,26 & 0,4 & 0,33 & 1,51 & 1,95 & 3,19 & 4,6 & 4,38 & 5,98 & 6,86 & 7,23 & 9,05 \\
\hline
\end{tabular}

Fuente: Instituto Brasileño de Geografía y Estadística (IBGE), Pesquisa Industrial Anual, 2010 [en línea] http://www.ibge.gov.br.

a A partir de 2007 se presenta la agregación del vTi según la Clasificación Nacional de Actividades Económicas (CNAE) 2.0.

Otra causa secundaria que puede aducirse para explicar el fenómeno es la fuerte presencia de redes urbanas en Paraná y Rio Grande do Sul, mientras que esa presencia es menor en Bahia y Goiás. Puesto que la red urbana es el sistema integrado y jerarquizado de ciudades — debidamente conectado por vías adecuadas de comunicación-, que permite la expansión y la integración de las inversiones, resulta fácil ver por qué las experiencias de los estados de la región Sur tuvieron mejores resultados que las de los estados de las regiones Centro-Oeste y Nordeste. Si bien es un dato relevante, no explica por completo el caso de Río de Janeiro, que no logró efectos significativos de integración a pesar de poseer una red urbana bastante desarrollada.

Según el Ministerio de Desarrollo, Industria y Comercio Exterior, el régimen automotor brasileño, en vigor de 2013 a 2017, establece nuevas condiciones de habilitación para las ensambladoras, así como reglas en lo relativo al impuesto sobre los productos industrializados (IPI) y reglas de transición para atraer inversiones en la producción de vehículos en el país. Hasta el momento, 43 grupos han solicitado participar en el programa y 33 ya han sido habilitados ${ }^{13}$. Según las expectativas del ministerio antes mencionado y la

\footnotetext{
${ }^{13}$ Productoras: Nissan, Agrale, Caoa (Hyundai), Fiat, Ford, General Motors, Honda, International, Iveco, Man Mercedez-Benz, Mitsubishi (Mмc), Peugeot, Citroën, Renault, Scania, Suzuki (svB), Toyota, Volkswagen y Volvo. Importadoras: Ssang Yong/Changan (Districar), Rely (Venko), Chrysler, Porsche (Stuttgart Sportcar), Jaguar, Land Rover, Volvo, Bentley (British Cars Brasil) y Aston Martin (SNS). Inversoras: Chery, JAC Mitsubishi (MMC) y Nissan.
}

ANFAVEA, las inversiones en el sector alcanzarán a los 60.000 millones de reales en el período.

La ANFAVEa (2012b, pág. 2) explica que en el nuevo régimen se establecen como objetivos el incremento del contenido regional medido por el volumen de adquisiciones de partes e insumos de las empresas del país para su producción, las inversiones en ingeniería e innovación, y el aumento de la eficiencia energética de los vehículos, de manera que todos estos factores se tendrán en cuenta para la obtención de la reducción del IPI.

Según Maia Júnior (2012), están en curso los proyectos de construcción de Ford (Goiana, Pernambuco), Nissan (Resende, Río de Janeiro), Chery (Jacareí, São Paulo), Toyota (Sorocaba, São Paulo) y Hyundai (Piracicaba, São Paulo). Además, se han anunciado los siguientes proyectos: Effa Motors (Manaos, Amazonas), JAC Motors (Camaçari, Bahia), CN Auto (Linhares, Espírito Santo) y Suzuki (Itumbiara, Goiás).

Estos datos permiten señalar que São Paulo sigue siendo el estado con el mayor número de inversiones del sector automotor, tanto en curso como anunciadas, lo que refuerza el carácter concentrado del sector, a pesar del proceso de relocalización productiva entre 1995 y 2011 descrito en el presente trabajo.

Este proceso corrobora el hecho de que el significativo papel de las economías de escala y de aglomeración en la producción de vehículos también tiene consecuencias para la toma de decisiones con respecto a la localización de las empresas. Los dos factores, en conjunto, tienden a estimular un sector caracterizado por una concentración de grandes empresas, aglomeradas en algunas regiones geográficas no muy dispersas, tal como se señala en Sturgeon, Biesebroeck y Gereffi (2008), entre otros. 


\section{V}

\section{Conclusiones}

La tercera ola de inversiones iniciada en la segunda mitad de la década de 1990 logró, de hecho, una ligera desconcentración espacial de la industria automovilística nacional, que se expandió más allá de los polos tradicionales de São Paulo y Minas Gerais, lo que repercutió positivamente en el valor de la transformación industrial (VTI) de los estados analizados.

No todas las inversiones realizadas desde los años noventa fueron significativas en el sentido de desconcentrar espacialmente la industria automovilística, como sucedió con las realizadas en Paraná y en Rio Grande do Sul. En cambio, las inversiones destinadas a Río de Janeiro, Bahia y Goiás, aunque hayan logrado hacer crecer los respectivos indicadores de coeficientes de localización y de VTI, no produjeron el mismo efecto estadístico registrado en los dos estados mencionados de la región Sur en cuanto a la especialización productiva, con respecto a los demás estados.

Probablemente, la causa principal de esta disparidad se relaciona con el hecho de que las empresas que se trasladaron a Río de Janeiro, Bahia y Goiás (Ford, Peugeot/Citroën, Mitsubishi y Hyundai) no lideran el mercado brasileño ni son las que más crecieron durante el período, a diferencia de aquellas que optaron por establecerse en Paraná y Rio Grande do Sul (Volkswagen, General Motors y Renault/Nissan). Otra explicación podría hallarse en la gran presencia de redes urbanas en Paraná y Rio Grande do Sul, mientras que esta es menor en Bahia y Goiás.

En CNI/CEPAL (2001) se indica que, desde 1996, ya podía observarse una tendencia a la intensificación de la diversificación espacial de las inversiones en las industrias. Los beneficios fiscales de los estados, la proximidad del mercado consumidor (en términos internacionales) y el costo de la mano de obra fueron los principales factores determinantes de este proceso.

En ese contexto, como muestra el patrón de las instalaciones de fábricas, los efectos de economías de aglomeración y de los beneficios fiscales del sector público tuvieron una gran influencia en la localización industrial de las ensambladoras durante el período analizado, más allá de los estados de São Paulo y Minas Gerais. Esos beneficios fiscales fomentaron en gran medida los procesos de competencia territorial que, junto con factores de macrolocalización y microlocalización, determinaron la instalación de las nuevas ensambladoras.

La instalación de esas nuevas unidades debe estar acompañada de políticas basadas en la internalización de la cadena de proveedores en la misma región. Así, se puede optimizar lo que Hirschman (1961) denominó efectos favorables (o de difusión). Asimismo, los encargados de la formulación de políticas también deben tener en mente los posibles efectos hacia atrás de la industria automotriz, tanto a escala regional como nacional. Cabe resaltar, por otra parte, que el proceso de competición mundial del sector automotor tiende a crear cadenas globales de insumos, lo que redunda en que los incentivos para la internalización de los insumos (proveedores locales) sean poco efectivos y afecten solo a algunos servicios y productos de contenido tecnológico limitado.

\section{Bibliografía}

Albuquerque, E. (2000), "Empresas transnacionais e suas patentes no Brasil: resultados iniciais de uma investigação sobre a internalização de atividades tecnológicas", Revista de Economia Contemporânea, vol. 4, № 2, Río de Janeiro, Universidad Federal de Río de Janeiro.

Albuquerque, E. y otros (2002), "Distribuição espacial da produção científica e tecnológica brasileira: uma descrição de estatísticas de produção local de patentes e artigos científico", Revista Brasileira de Inovação, vol. 1, № 2, Campinas, Universidad Estatal de Campinas.

anfaVea (Asociación Nacional de Fabricantes de Vehículos Automotores) (2012a), Anuário da indústria automobilística brasileira, São Paulo.

(2012b), Anuário estatístico da Associação Nacional de Fabricantes de Veículos Automotivos, São Paulo.
"Estatísticas" [en línea] http://www.anfavea.com.br.

Basset, K., R. Griffiths e I. Smith (2002), "Cultural industries, cultural clusters and the city: the example of natural history film-making in Bristol", Geoforum, vol. 33, N 2, Amsterdam, Elsevier.

Camargo, O.S. (2006), "As mudanças na organização e localização da indústria automobilística brasileira (1996-2001)", tesis de doctorado, Belo Horizonte, Centro de Desarrollo y Planificación Regional (CEDEPLAR)/Universidad Federal de Minas Gerais (UFMG).

Casotti, B.P. y M. Goldenstein (2008), "Panorama do setor automotivo: as mudanças estruturais da indústria e as perspectivas para o Brasil”, BNDES Setorial, № 28, Río de Janeiro.

Christäller, W. (1952), Central Places in Southern Germany, Prentice Hall. 
CNI/CEPAL (Confederación Nacional de la Industria/Comisión Económica para América Latina y el Caribe) (2001), Investimentos na Indústria Brasileira 1998-2002, Brasilia.

Combes, P.P. (2000), "Economic structure and local growth: France, 1984-1993", Journal of Urban Economics, vol. 47, N 3 , Amsterdam, Elsevier.

Costa, R.M. y H. Henkin (2011), Estratégias competitivas e desempenho da indústria automobilística no Brasil [en línea] http://www.anpec.org.br/encontro/2012/inscricao/files_I/i8-0ef effb91919f560fd57485db2d76124.pdf.

Ferraz, J.C., D. Kupfer y L. Haguenauer (1996), Made in Brazil, desafios competitivos para a indústria, Río de Janeiro, Editora Campus.

Fochezatto, A. (2010), "Desenvolvimento regional: recomendações para um novo paradigma produtivo", Três décadas de economia gaucha. O ambiente regional, $\mathrm{O}$. Conceicão y otros, Porto Alegre, Fundación de Economía y Estadística (FEE).

Freitas, E. (2012), "Economia externas, atributos urbanos e produtividade: evidências a partir do nível salarial industrial das microrregiões brasileiras de 2000 a 2010", Belo Horizonte, Universidad Federal de Minas Gerais.

García, M., Y. Fernández y J. Zobio (2003), "The economic dimension of the culture and leisure industry in Spain: national, sectoral and regional analysis", Journal of Cultural Economics, vol. 27, $\mathrm{N}^{\circ}$ 1, Springer.

Guilhoto, J.J.M. y otros (2010), Matriz de insumo-produto do Nordeste e Estados: metodologia e resultados, Fortaleza, Banco do Nordeste.

Guilhoto, J.J.M. y U.A. Sesso Filho (2005), "Estimação da matriz insumo-produto a partir de dados preliminares das contas nacionais", Economia Aplicada, vol. 9, $\mathrm{N}^{\circ} 2$.

Haddad, P.R. (org.) (1989), Economia regional: teorias e métodos de análise, Fortaleza, Banco do Nordeste.

Haddad. E.A. y otros (2007), "Building up influence: post-war industrialization in the state of Minas Gerais, Brazil", Revista de Economia Política, vol. 27, $\mathrm{N}^{\circ}$ 2, São Paulo.

Hirschman, A.O. (1961), La estrategia del desarrollo económico, Ciudad de México, Fondo de Cultura Económica.

IBGE (Instituto Brasileño de Geografía y Estadística) (2010), Pesquisa Industrial Anual [en línea] http://www.ibge.gov.br.

Langlois, R. y P. Robertson (1989), "Explaining vertical integration: lesson from the American Automobile Industry", Journal of Economic History, vol. 49, № 2, Nueva York, Cambridge University Press.

Latini, S.A. (2007), A implantação da indústria automobilística no Brasil: da substituição de importações ativa à globalização passiva, São Paulo, Alaúde Editorial.

Lazzeretti, L., R. Boix y F. Capone (2008), "Do creative industries cluster? Mapping creative local production systems in Italy and Spain", Industry and Innovation, vol. 15, $\mathrm{N}^{\circ} 5$,

Lösch, A. (1954), The Economics of Location, New Haven, Yale University Press.
Maia Júnior, H. (2012), "Por que as montadoras crescem?", Revista Exame, abril.

Marshall, A. (1985), Princípios de Economia, vol. 1, São Paulo, Nova Cultural.

Marx, R. y A.M. Mello (2008), Uma agenda de competitividade para a indústria paulista: veículos (automóveis e comerciais leves), São Paulo, Instituto de Investigaciones Tecnológicas del Estado de São Paulo.

Miller, R.E. y P.D. Blair (2009), Input-Output Analysis: Foundations and Extensions, Nueva York, Cambridge University Press.

Ministerio del Trabajo y Empleo (2006), Relação Anual de Informações Sociais, Brasilia [serie histórica disponible en CD].

Myrdal, G. (1957), Economic Theory and Underdeveloped Regions, Londres, Gerald Duckworth \& Co.

Rezende, A.C., B. Campolina y A.N. Paixão (2013), "Clusterização e localização da indústria de transformação no Brasil entre 1994 e 2009", Revista Econômica do Nordeste, vol. 43, N 4.

Ribeiro y otros (2010), "Economia baiana em 2005 sob a ótica das relações intersetoriais: uma abordagem insumo-produto", Revista Desenbahia, $\mathrm{N}^{\circ} 12$, Salvador, Desenbahia.

Ribeiro, L.C.S. y G. Britto (2013), "Interdependência produtiva e estratégias de desenvolvimento para o estado da Bahia", Revista Economia Ensaios, vol. 27, $\mathrm{N}^{\circ} 2$.

Ribeiro, L.C.S., R.L. Montenegro y R.M. Pereira (2013), "Estrutura econômica e encadeamentos setoriais de Minas Gerais: uma contribuição para as políticas de planejamento", Planejamento e Políticas Públicas, $\mathrm{N}^{\circ} 41$

Rodríguez-Pose, A. y G. Arbix (1999), "Estratégias do desperdício: a guerra fiscal e as incertezas do desenvolvimento", Novos Estudos, $\mathrm{N}^{\circ}$ 54, São Paulo, Centro Brasileño de Análisis y Planeamiento.

Salerno, M.S. y otros (2008), Uma agenda de competitividade para a indústria paulista: Indústria de Autopeças, São Paulo, Instituto de Investigaciones Tecnológicas del Estado de São Paulo.

Santos, A.M. y P. Burity (2003), "O complexo automotivo", inédito.

Senhoras, E.M. (2005), "A indústria automobilística sob enfoque estático e dinâmico: uma análise teórica", Anais do VIII SEMEAD, São Paulo [en línea] http://www.ead.fea.usp.br/ semead/8semead/resultado/trabalhosPDF/226.pdf.

Simões, R. (2005), "Métodos de análise regional e urbana: diagnóstico aplicado ao planejamento", Texto para Discussão, Nㅜ 259, Belo Horizonte, Centro de Desarrollo y Planificación Regional (CEDEPLAR)/Universidad Federal de Minas Gerais (UFMG).

Sturgeon, T., J. Biesebroeck y G. Gereffi (2008), "Value chains, networks and clusters: reframing the global automotive industry", Journal of Economic Geography, vol. 8, $\mathrm{N}^{\circ} 3$, Oxford University Press.

Weber, A. (1929), Theory of the Location of Industries, Chicago, The University of Chicago Press. 